\section{Dynamic ultrasonography of the shoulder}

\author{
Jina Park, Jee Won Chai, Dong Hyun Kim, Seung Woo Cha
}

Department of Radiology, SMG-SNU Boramae Medical Center, Seoul National University

College of Medicine, Seoul, Korea

Ultrasonography (US) is a useful diagnostic method that can be easily applied to identify the cause of shoulder pain. Its low cost, excellent diagnostic accuracy, and capability for dynamic evaluation are also advantages. To assess all possible causes of shoulder pain, it is better to follow a standardized protocol and to perform a comprehensive evaluation of the shoulder than to conduct a focused examination. Moreover, a proper dynamic study can enhance the diagnostic quality of US, especially when the pathology is not revealed by a static evaluation. The purpose of this article is to review the common indications for dynamic US of the shoulder, and to present the basic techniques and characteristic US findings.

Keywords: Shoulder; Ultrasonography; Movement

\section{Introduction}

Ultrasonography (US) is a commonly performed examination for shoulder pain, recommended by experts as the first-choice technique to evaluate various rotator cuff diseases and nonrotator cuff diseases [1-4]. When US is performed by an experienced radiologist, its diagnostic sensitivity and specificity for detecting rotator cuff tears are comparable to those of magnetic resonance imaging (MRI) [5].

The advantages of US include not only excellent diagnostic accuracy but also high resolution and the capability of dynamic evaluation [6]. To assess all possible causes of shoulder pain, it is better to follow a standardized protocol and to perform a comprehensive evaluation of the shoulder than to conduct a focused examination. Moreover, a proper dynamic study can enhance the diagnostic quality of US, especially when the pathology is not revealed by a static evaluation. The purpose of this article is to review the common indications for dynamic US of the shoulder, and to present the basic techniques and characteristic US findings.

\section{Long Head of the Biceps Tendon Subluxation}

The long head of the biceps tendon (LHBT) can be assessed with the patient in the neutral position, with his or her elbow flexed and the dorsum of the hand placed on the ipsilateral thigh. The LHBT is visible as a cord-like hyperechoic structure that lies within the bicipital groove between the greater and lesser tubercle of the proximal humerus and is covered by the transverse humeral ligament. In normal shoulders, the LHBT is secured by the tendon sheath and pulley, as well as the transverse humeral ligament, so that it is not subluxated or dislocated during internal or external rotation of the shoulder $[2,6-8]$.

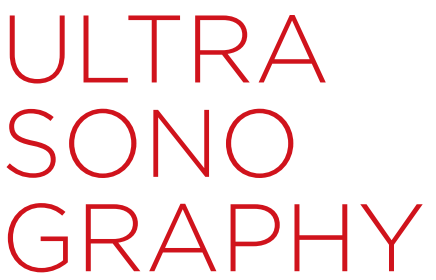

\section{REVIEW ARTICLE}

https://doi.org/10.14366/usg. 17055 pISSN: 2288-5919 • elSSN: 2288-5943 Ultrasonography 2018;37:190-199

Received: August 1, 2017

Revised: August 26, 2017

Accepted: August 26, 2017

Correspondence to: Jee Won Chai, MD, PhD, Department of Radiology, SMG-SNU Boramae Medical Center, Seoul National University College of Medicine, 20 Boramae-ro 5-gil, Dongjak-gu, Seoul 07061, Korea

Tel. +82-2-870-2549

Fax. +82-2-870-3539

E-mail: chaijw@gmail.com

\begin{abstract}
This is an Open Access article distributed under the terms of the Creative Commons Attribution NonCommercial License (http://creativecommons.org/ licenses/by-nc/3.0/) which permits unrestricted noncommercial use, distribution, and reproduction in any medium, provided the original work is properly cited.
\end{abstract}

Copyright @ 2018 Korean Society of Ultrasound in Medicine (KSUM)

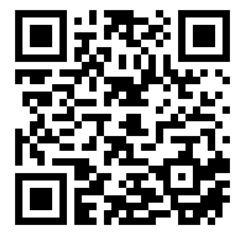

How to cite this article:

Park J, Chai JW, Kim DH, Cha SW. Dynamic ultrasonography of the shoulder. Ultrasonography. 2018 Jul:37(3):190-199. 
Dynamic evaluation for subluxation or dislocation of the LHBT was first introduced in 1995, by Farin et al. [9]. They found that maximal external rotation of the shoulder was helpful for diagnosing transient subluxation of the LHBT, and the sensitivity of the dynamic assessment was $86 \%$. The authors suggested that a dynamic study for LHBT subluxation should be included in routine shoulder US. LHBT subluxation and dislocation are frequently reported with a shallow bicipital groove and rotator cuff tears, especially subscapularis tendon tears $[9,10]$. A bicipital groove less than 3 $\mathrm{mm}$ deep is regarded as shallow [9]. The diagnosis of subluxation or dislocation can be made when the LHBT overlies the wall of the bicipital groove or moves out of the groove in the short-axis view, either in the neutral or external rotation position [9-11] (Fig. 1). Skendzel et al. [12] reported LHBT subluxations accompanied by partial tears of the LHBT, and postulated that LHBT subluxation associated with surface irregularities should raise suspicion of a partial-thickness tear of the LHBT.

\section{Intra-articular Entrapment of the LHBT}

Intra-articular entrapment of the LHBT, known as "hourglass biceps," was first described by Boileau et al. [13]. This is a novel mechanical impairment of biceps tendon movement that presents as pain and locking of the shoulder. The sliding motion of the LHBT in the limited space of the bicipital groove is blocked by severe swelling of the intra-articular LHBT during shoulder abduction, subsequently causing buckling of the intra-articular LHBT and leading to pain in the anterior shoulder. US criteria for intra-articular entrapment of the LHBT were suggested by Pujol et al. [14], and

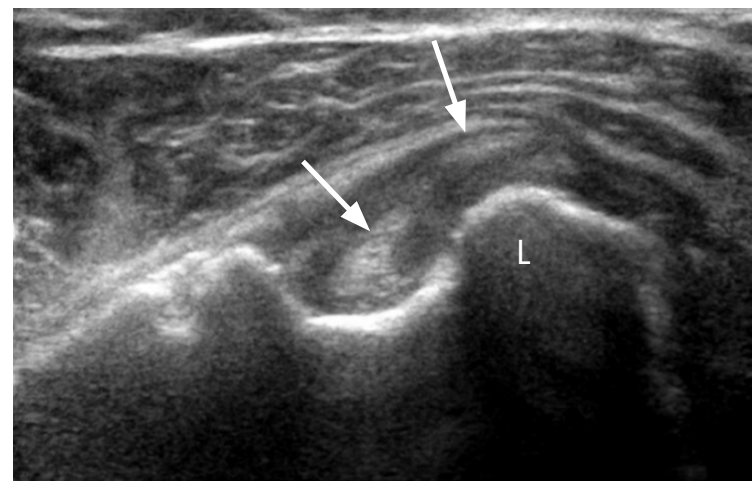

A include a $10 \%$ increase in the diameter of the intra-articular LHBT or tendon buckling that is visible during shoulder abduction (Fig. 2). The sensitivity of the dynamic evaluation (50\%) was not satisfactory, but the specificity was $100 \%$.

\section{Subcoracoid Impingement}

Subcoracoid impingement or coracoid impingement is a rarely diagnosed, but well-known cause of anterior shoulder pain $[15,16]$. The known etiologies of subcoracoid impingement are anatomic variations of the scapulae (coracoid process), ossifications of the subscapularis tendon (Fig. 3, Video clip 1), ganglion cysts, and other osseous deformities caused by surgery or trauma [17] that produce excessive pressure on the LHBT or subscapularis tendon.

The main diagnostic criterion for subcoracoid impingement in imaging studies is coracohumeral distance, although discordant opinions about its diagnostic value have been reported in the literature $[18,19]$. The coracohumeral distance is known to be smaller in symptomatic patients than in asymptomatic volunteers [18]. Because the coracohumeral distance on MRI is known to be smaller in women than in men, a sex-adjusted criterion $(11.5 \mathrm{~mm}$ in men) was proposed by Giaroli et al. [19], but it showed poor predictive value. Recently, subcoracoid bursitis and impingement were observed with dynamic US during internal/external rotation of the shoulder [20], which is one of the well-known appearances of subacromial impingement. Because anatomical or biomechanical properties are different in each patient, real-time observation of the mechanical blockage (Fig. 4, Video clip 2) might have the potential to be able to diagnose this mechanical condition, although further

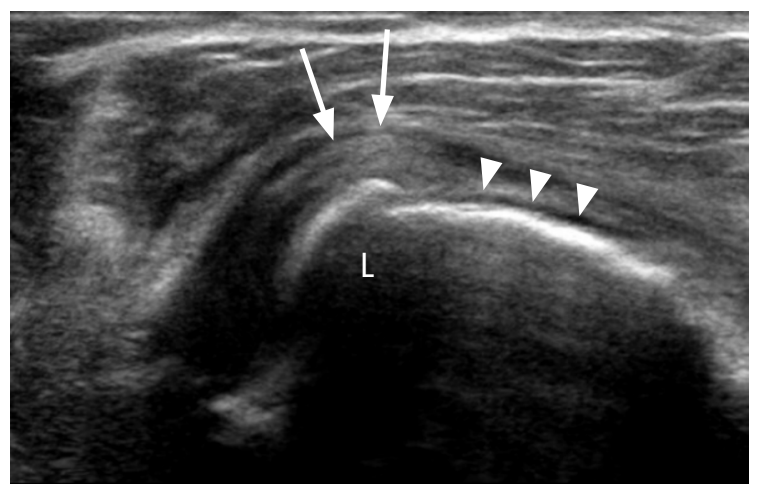

B

Fig. 1. An 84-year-old man with biceps tendon subluxation.

A. In the neutral position, the biceps long head tendon (arrows) shows a split tear and the medial portion of the tendon partially overlies the medial wall of the bicipital groove formed by the lesser tubercle (L), although the biceps tendon is located in the groove. The depth of the bicipital groove is normal. B. In the external rotation position, the medial portion of the torn biceps long head tendon (arrows) is displaced more medially over the lesser tubercle (L). Note that the subscapularis tendon is completely torn at the footprint of the lesser tubercle (arrowheads). 


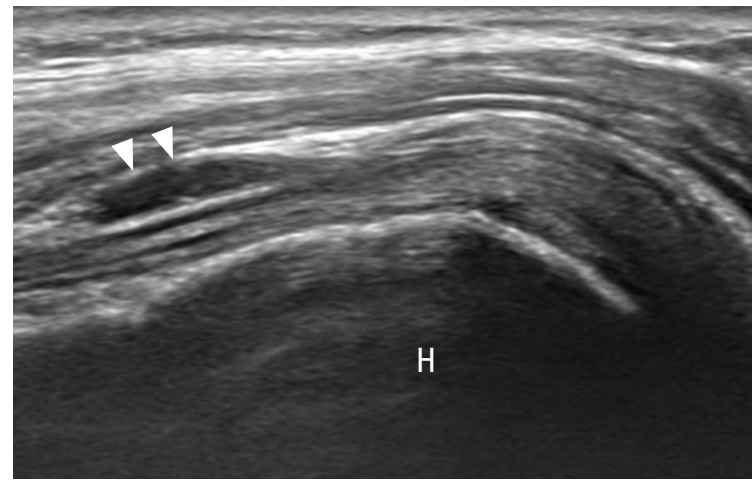

A

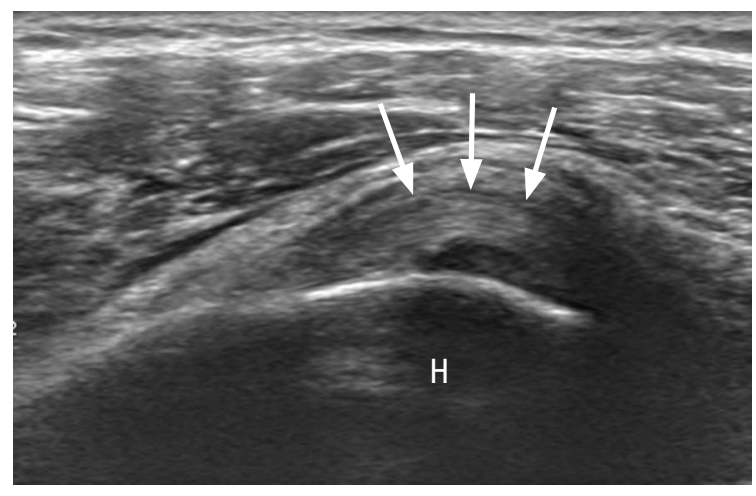

C

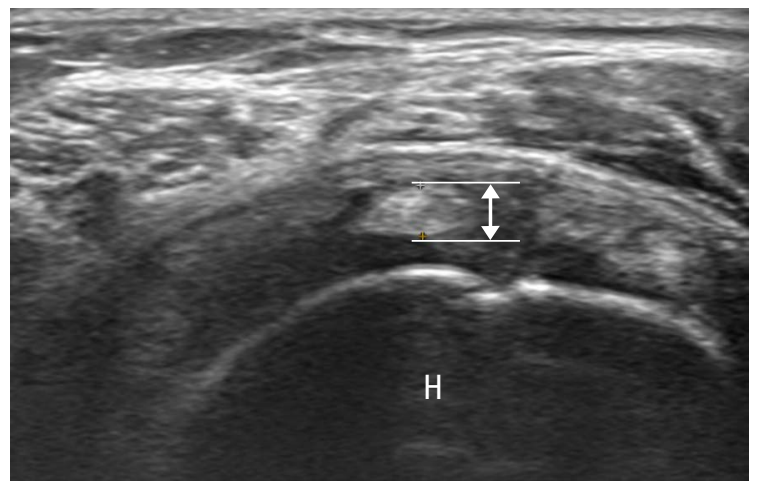

B

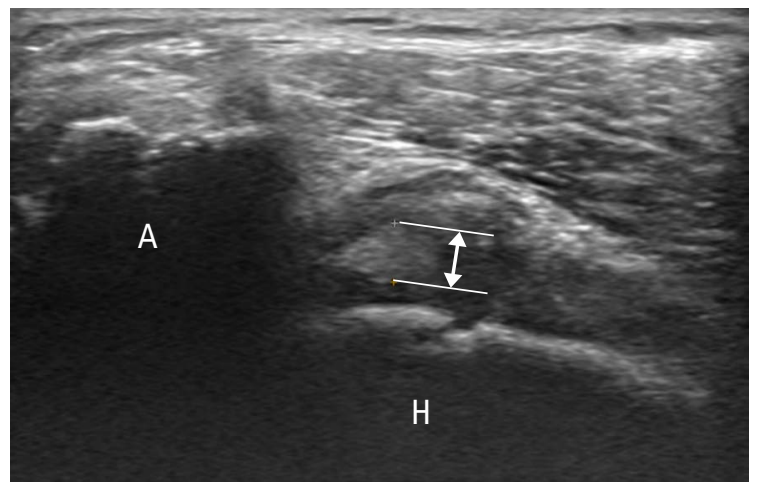

D

Fig. 2. A 71-year-old woman with anterior shoulder pain.

$A, B$. The long-axis view and the short-axis view of the long head of the biceps tendon (LHBT) in the neutral position of the shoulder are shown. The LHBT is thickened, with a hypoechoic appearance suggesting tendinopathy. A small amount of effusion (arrowheads) is noted in the biceps tendon sheath. The diameter of the intra-articular tendon was $2.8 \mathrm{~mm}$. C, D. The long-axis view and the short-axis view of the LHBT in the abduction position of the shoulder are shown. The intra-articular LHBT has a more curved appearance (arrows) and is elevated from the humeral head $(\mathrm{H})$. The diameter of the intra-articular tendon was $3.5 \mathrm{~mm}$, with an increase of $25 \%$ compared to the neutral position. A, acromion.

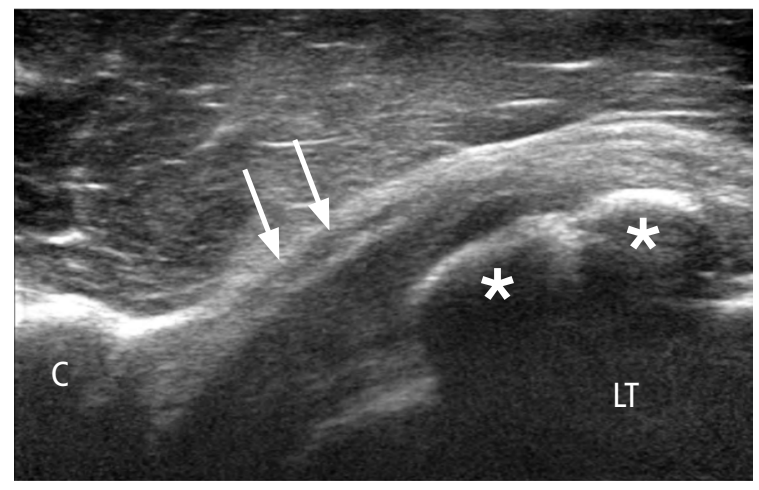

A

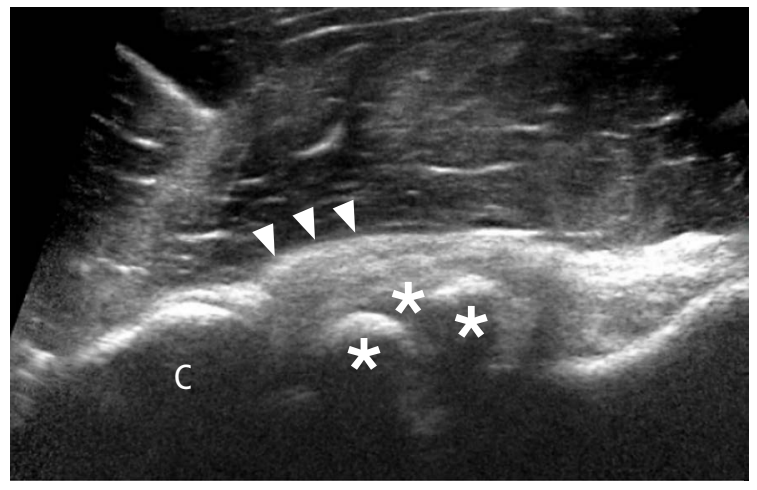

B

Fig. 3. A 19-year-old man with subscapularis tendon ossification and subcoracoid impingement.

A. The long-axis view of the subscapularis tendon shows slightly thickened subcoracoid bursa (arrows), superficially located above the subscapularis tendon (arrows). There are two ossifications in the subscapularis tendon (asterisks). B. During internal rotation of the shoulder, the subscapularis tendon does not fully glide under the coracoid process due to ossifications (asterisks), and subcoracoid impingement occurs. Note the bulging contour of the hypoechoic soft tissue by the subcoracoid bursa and the subscapularis tendon (arrowheads). C, coracoid process; LT, lesser tubercle of the humerus. 


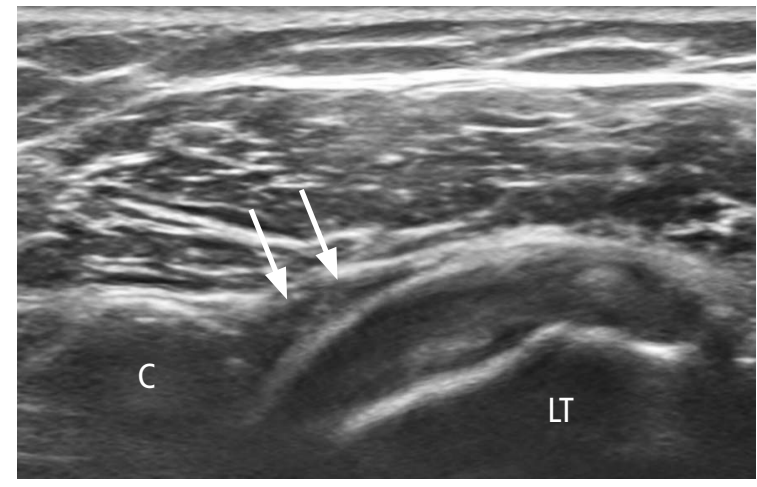

Fig. 4. A 69-year-old woman with subcoracoid impingement with soft tissue involvement. Long-axis view of the subscapularis tendon during internal rotation of the shoulder shows pooling of the fluid in the subcoracoid bursa (arrows) at the lateral aspect of the coracoid process. C, coracoid process; LT, lesser tubercle of the humerus.

validation is needed.

\section{Subacromial Impingement}

Subacromial impingement is the most common and well-recognized indication for dynamic US in the shoulder. Osteophytes, or an abnormal shape of the acromion, subacromial spurs, and the acromioclavicular joint, are common causes of compression at the rotator cuff and the overlying subacromial-subdeltoid bursa [21]. Dynamic evaluation can be done by shoulder abduction or flexion with the probe placed at the end of the acromion in the coronal plane or in the sagittal plane. The two important points to be checked for subacromial impingement are the humeral head depression and tendon/bursal impingement [22]. Because humeral head depression is essential to make enough space for the rotator cuff to slide beneath the acromion, the center of the humeral head normally moves inferiorly in the latter half of the cycle during shoulder abduction. When the humeral head does not move inferiorly or abnormally moves superiorly, the space for the rotator cuffs and the subacromial-subdeltoid bursa decreases and subacromial impingement can occur. Bureau et al. [23] observed proximal migration of the humeral head with dynamic US, and classified this osseous impingement as the most severe (grade 3 ) form of subacromial impingement (Table 1). They also described soft tissue (bursa or tendon) encroachment beneath the acromion, possibly combined with failure of humeral head depression, as grade 2 impingement (Fig. 5, Video clips 3-5).

The dynamic evaluation of subacromial impingement on US is commonly focused at the end of the acromion. However, subacromial impingement not only occurs beneath the acromion, but also at all possible locations below the coracoacromial arch,
Table 1. Ultrasonographic classification of subacromial impingement

\begin{tabular}{ccl}
\hline Grade & $\begin{array}{c}\text { Pain provocation with } \\
\text { shoulder motion }\end{array}$ & \multicolumn{1}{c}{ Ultrasonographic finding } \\
\hline 0 & No & No visible anatomic impingement \\
1 & Yes & No visible anatomic impingement \\
2 & Yes & Bursa or tendon impingement \\
3 & Yes & Superior migration of the humeral head \\
\hline
\end{tabular}

Modified from Bureau et al. AJR Am J Roentgenol 2006;187:216-220, with permission of American Roentgen Ray Society [23].

including anywhere between flexion and abduction of the shoulder (Fig. 6). The coracoacromial ligament is the central part of the coracoacromial arch, which can be the main causative structure for subacromial impingement and has recently received attention as part of ultrasonographic evaluations $[22,24,25]$. The coracoacromial ligament can be visualized by placing one end of the probe at the acromion and the other end at the coracoid process (Figs. 6, 7A). Subacromial impingement beneath the coracoacromial ligament can be also visualized by turning the probe $90^{\circ}$ from the long-axis view of the coracoacromial ligament, which is slightly anterior from the acromion, and along the direction of the supraspinatus tendon (Fig. 7B) [22]. The thickness and length of the coracoacromial ligament is not different between normal subjects and those who have subacromial impingement syndrome, but superior displacement of the coracoacromial ligament is significantly increased during shoulder abduction-internal rotation (throwing motion) [24-26].

\section{Adhesive Capsulitis}

Adhesive capsulitis or frozen shoulder is a frequently encountered disease in the shoulder, causing pain and a limited range of motion. It is more common in individuals with diabetes and perimenopausal women [22]. The ultrasonographic findings of adhesive capsulitis are hypoechoic changes and hypervascularity in the rotator interval [27], and thickening of the coracohumeral ligament (mean thickness of $3.0 \mathrm{~mm}$, compared to $1.4 \mathrm{~mm}$ in asymptomatic patients) [28] and the inferior glenohumeral ligament (mean thickness of $4.0 \mathrm{~mm}$ compared to $1.3 \mathrm{~mm}$ in the asymptomatic contralateral shoulder) [29]. However, the diagnosis of adhesive capsulitis still substantially relies on the radiologist's observation of limited external rotation or abduction during routine shoulder US.

The dynamic US findings of adhesive capsulitis were reported in 1993 by Ryu et al. [30]. They found that continuous limitation of supraspinatus movement beneath the acromion and continuous visualization of the supraspinatus tendon during shoulder abduction were useful criteria that could diagnose adhesive capsulitis 


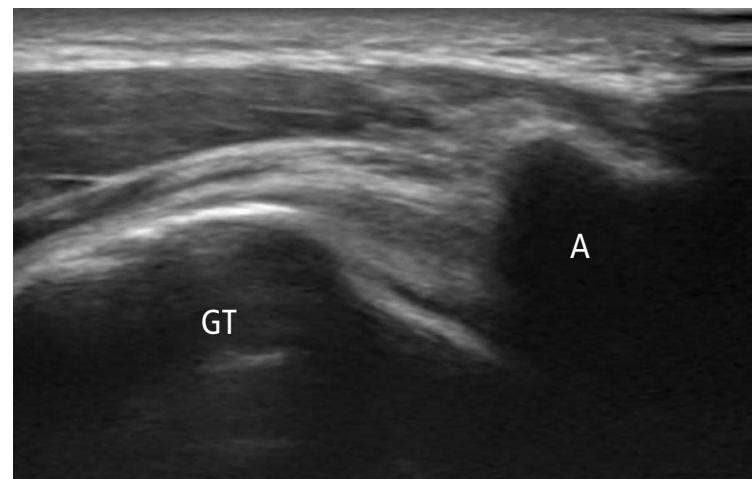

A

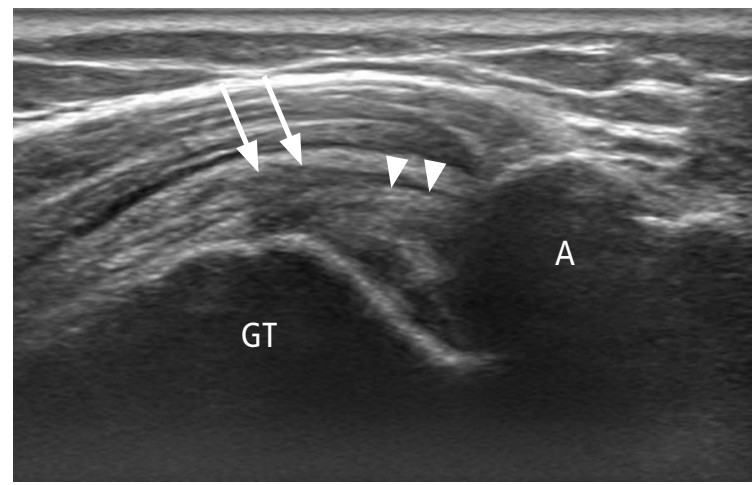

C

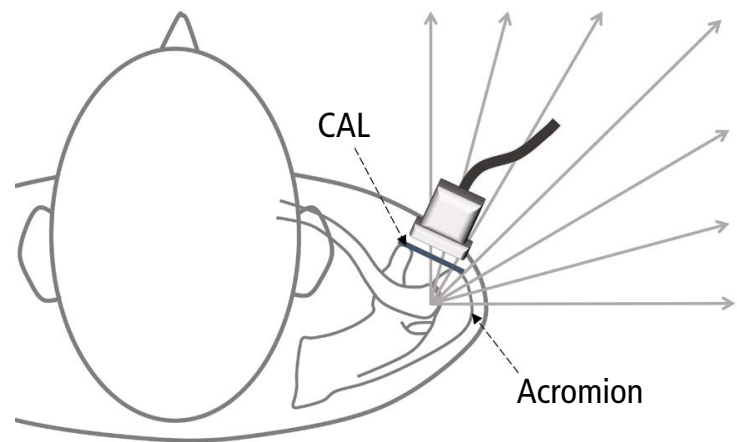

Fig. 6. Schematic drawing of the shoulder showing the coracoacromial ligament (CAL) seen from above. The CAL is located just anterior to the aspect of the acromion connecting the coracoid process and the acromion. Subacromial impingement can occur not only below the acromion, but also below the $C A L$, by elevation of the arm in any direction (arrows) between flexion and abduction of the shoulder.

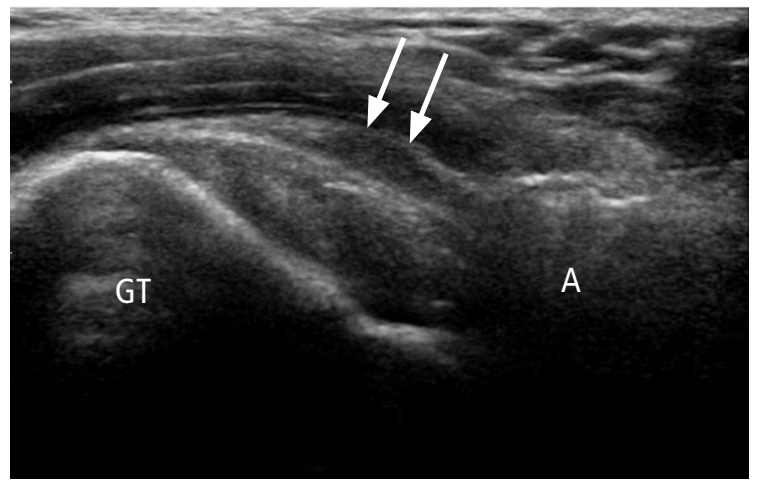

B

Fig. 5. Dynamic evaluation of subacromial impingement.

A. Normal dynamic ultrasonography of a 31-year-old man is shown. No visible soft tissue or osseous impingement was observed during shoulder abduction. B. A 45-year-old woman showed grade 2 subacromial impingement. Subacromial-subdeltoid bursal thickening (arrows) is visible above the supraspinatus tendon surface and gathers outside of the acromion during shoulder abduction. C. A 50 -year-old woman showed grade 3 subacromial impingement. The supraspinatus tendon shows severe tendinosis and is impinged between the greater tubercle of the humerus and the acromion. The humeral head does not sufficiently move inferiorly, and the supraspinatus tendon and the subacromial-subdeltoid bursa cannot be passed underneath the acromion. The tendon (arrowheads) and bursal tissues (arrows) are impinged and protruded superficially between the acromion and the greater tubercle of the humerus. $A$, acromion; GT, greater tubercle of the humerus.

with $92 \%$ accuracy. When the axillary pouch is stiff and cannot be stretched to let the shoulder abduct, the patient will try to compensate by scapulothoracic rotation to raise the arm. However, the glenohumeral joint relationship is fixed, and the supraspinatus tendon is persistently visible at the lateral aspect of the acromion (Fig. 8, Video clip 6). If there is no visible tendon pathology or soft tissue impingement, we can more confidently make the diagnosis of adhesive capsulitis using this dynamic evaluation.

\section{Acromioclavicular Joint Instability}

Acromioclavicular (AC) joint instability is another indication for dynamic US. For traumatic injuries of the $A C$ joint, the classification mainly relies on the $A C$ joint space and the extent of the ligament injury [31]. Because a normal $A C$ joint can show variable obliqueness and step-offs, AC joint space measurement on US can be problematic, and the criterion for widening ( $6 \mathrm{~mm}$ ) established on radiographs [32] cannot be directly used on US [33]. Therefore, a 


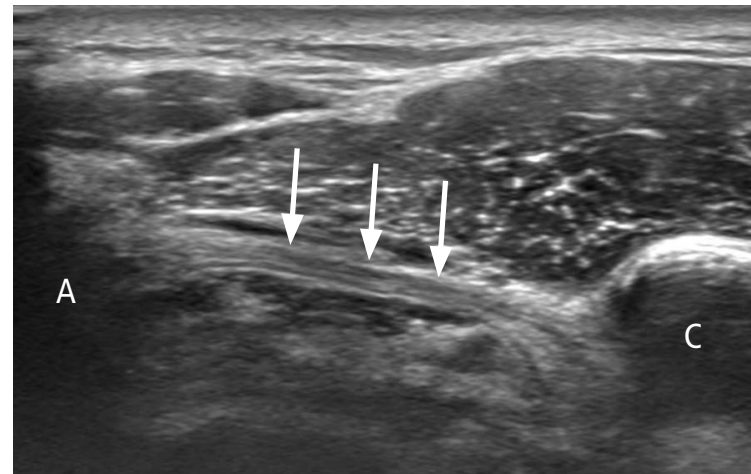

A

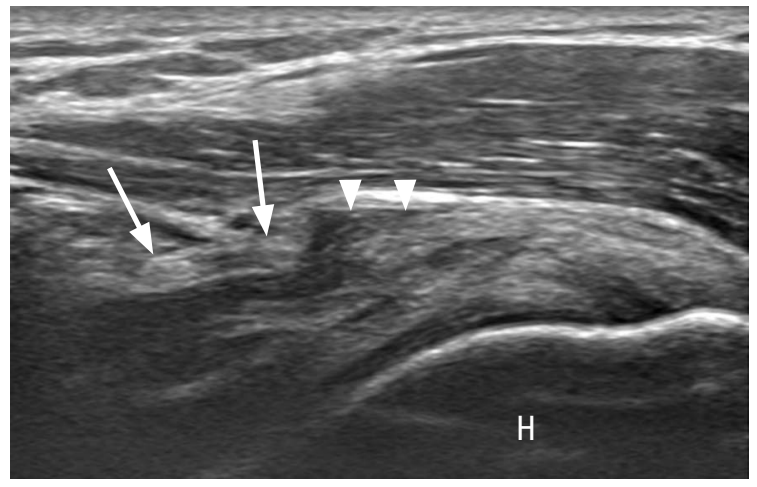

B

Fig. 7. A 19-year-old man with subacromial impingement syndrome by the coracoacromial ligament.

A. The coracoacromial ligament (arrows) is visible as a hyperechoic linear structure connecting the acromion (A) and the coracoid process (C) on the long-axis view, with the probe placed at the anterolateral shoulder in an oblique coronal plane. B. The short-axis view of the coracoacromial ligament (arrows) shows a plate-like structure covering the supraspinatus tendon and the subacromial bursa. Arm elevation midway between flexion and abduction of the shoulder provoked pain and bunching up of the underlying subacromial bursa (arrowheads) and the surface of the supraspinatus tendon.

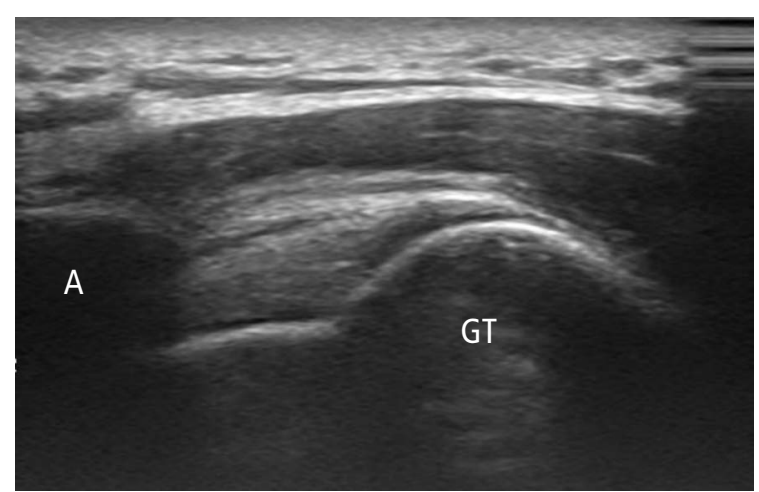

Fig. 8. A 54-year-old man with adhesive capsulitis. The long-axis view of the supraspinatus tendon during full shoulder abduction shows limited supraspinatus movement beneath the acromion and continuous visualization of the supraspinatus tendon. There is no significant subacromial soft tissue impingement. A, acromion; GT, greater tubercle of the humerus.

comparison with the contralateral side is recommended to diagnose abnormal widening of the $A C$ joint [34], and a relative measurement ( $A C$ index $=A C$ joint space on the uninjured side/ $A C$ joint space on the injured side) is suggested [35]. The normal $A C$ index is 1, and the $A C$ index is lower in more widened and severely injured $A C$ joints.

A dynamic evaluation procedure for $A C$ joint injuries was introduced by Peetrons and Bedard in 2007 [34]. By placing the palm at the contralateral shoulder, in the so-called cross-arm maneuver, the $A C$ distance is decreased in the injured AC joint (Fig. 9), and becomes widened again with the change of position to neutral (hands on the ipsilateral thigh). An uninjured AC joint shows minimal change (less than $1 \mathrm{~mm}$ ) in the cross-arm maneuver [34].
Osteoarthritis is another cause of AC joint instability, and the joint space can be severely decreased, with the cross-arm maneuver showing a "kissing" appearance. However, we can easily differentiate osteoarthritis with chronic instability from acute AC joint injury by joint space narrowing, subchondral bone changes, and the presence of osteophytes in the neutral position,

\section{Joint Effusion and Synovial Hypertrophy}

It is important to identify joint effusion for the diagnosis of septic arthritis or inflammatory arthritis in the glenohumeral joint. Joint effusion is commonly detected in the posterior recess of the glenohumeral joint and tendon sheath of LHBT by communication with the glenohumeral joint [36]. However, joint effusion can be invisible in the posterior recess in neutral position, even if the joint is distended with 8-12 mL of fluid [37]. Most likely, the fluid is pooled in the axillary pouch because of gravity when the patient is in sitting position. External rotation of the shoulder increased the sensitivity from $17 \%$ to $100 \%$ for detecting fluid in the glenohumeral joint in the posterior recess (Fig. 10).

\section{Differential Diagnosis of Cystic Lesions at the Spinoglenoid Notch}

The spinoglenoid notch is the groove between the glenoid and the base of the scapular spine, where the suprascapular nerve and suprascapular vessels run. This region should be evaluated during routine shoulder US for a possible paralabral cyst $[2,6,22,36]$, because a paralabral cyst at this location can entrap the suprascapular 


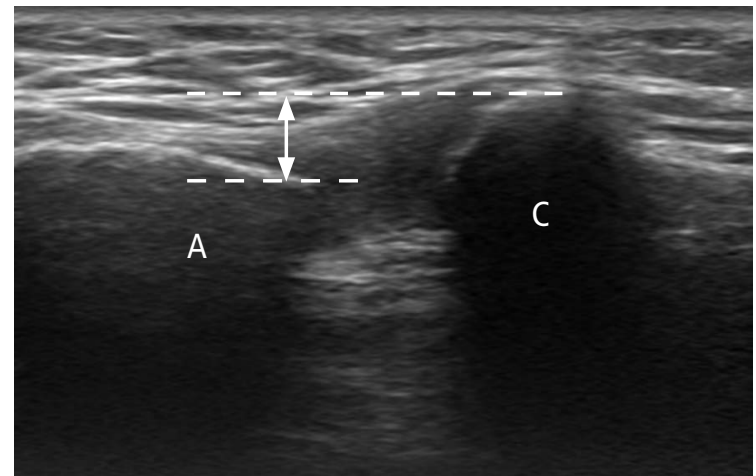

A

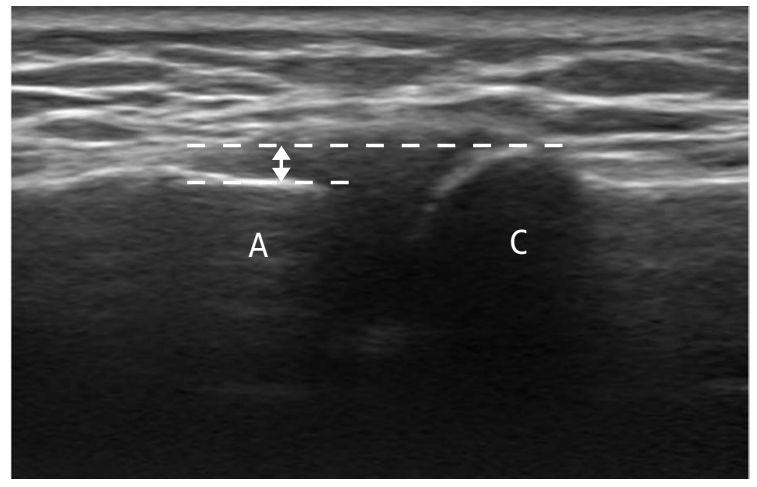

B

Fig. 9. A 37-year-old woman with chronic acromioclavicular (AC) joint injury.

A. A long-axis view of the AC joint in resting position shows joint space widening and step-off between the acromion $(A)$ and the clavicle (C). B. The AC joint space is narrowed and step-off is decreased by the cross-arm maneuver (placing the palm on the contralateral shoulder).

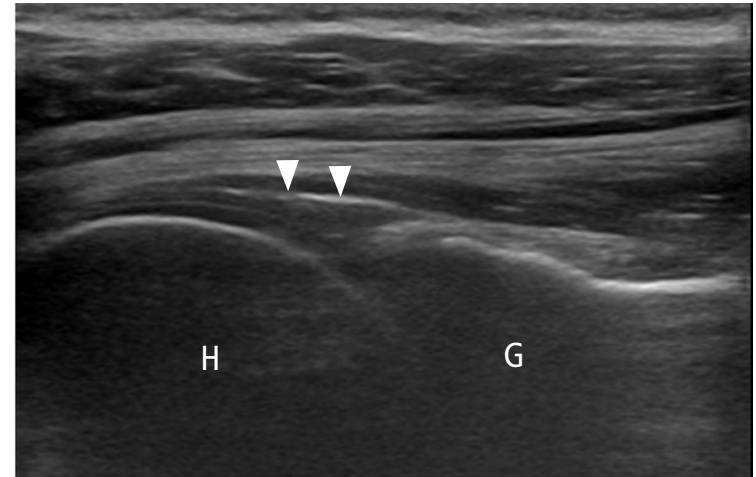

A

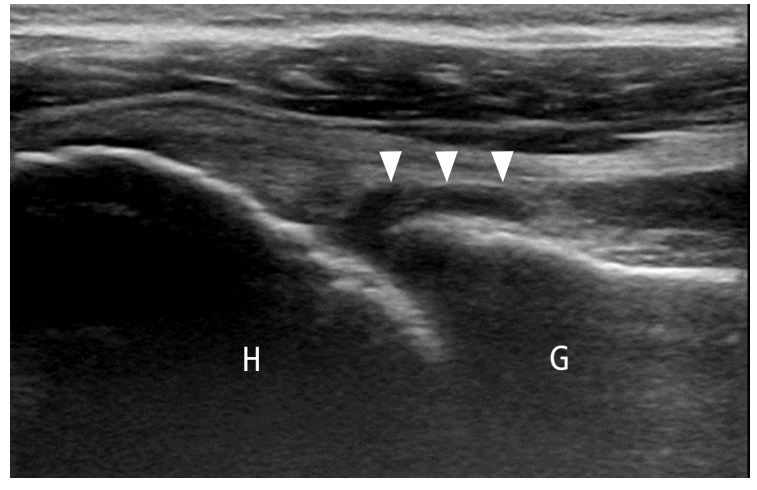

B

Fig. 10. A 70-year-old man with glenohumeral joint synovitis.

A. A long-axis view of the posterior glenohumeral joint shows a small amount of effusion (arrowheads) in neutral position, while the patient is being examined in the sitting position. B. External rotation of the shoulder joint more clearly revealed joint effusion and synovial hypertrophy (arrowheads) gathered at the posterior recess. H, head of humerus; G, glenoid.

nerve and cause pain or weakness of the shoulder. Occasionally, we can see the suprascapular vessels and nerves as tiny hypoechoic structures in the spinoglenoid notch [36]. Sometimes the vessels are engorged or distended with blood, especially in the external rotation position of the shoulder, and can be confused with a paralabral cyst or ganglion cyst [38]. Usually, the internal rotation position of the shoulder (cross-arm maneuver) decreases suprascapular varicosity (Fig. 11), whereas a true paralabral cyst or ganglion cyst does not change with internal rotation of the shoulder [6,22].

\section{Conclusion}

Dynamic real-time observation is a major strength of US, especially when the pathology is not revealed by a static evaluation. We do not perform all of these dynamic studies as part of routine shoulder US.
However, familiarity with these dynamic maneuvers and indications, and their proper application, will significantly improve the diagnostic value of shoulder US.

ORCID: Jina Park: http://orcid.org/0000-0003-1319-9410; Jee Won Chai: http://orcid. org/0000-0003-1630-1863; Dong Hyun Kim: http://orcid.org/0000-0002-3871-7002; Seung Woo Cha: http://orcid.org/0000-0003-0236-9330

\section{Conflict of Interest}

No potential conflict of interest relevant to this article was reported.

\section{Supplementary Material}

Video clip 1. A 19-year-old man with subscapularis tendon ossification and subcoracoid impingement. Long axis view of the subscapularis tendon shows slightly thickened subcoracoid bursa, 


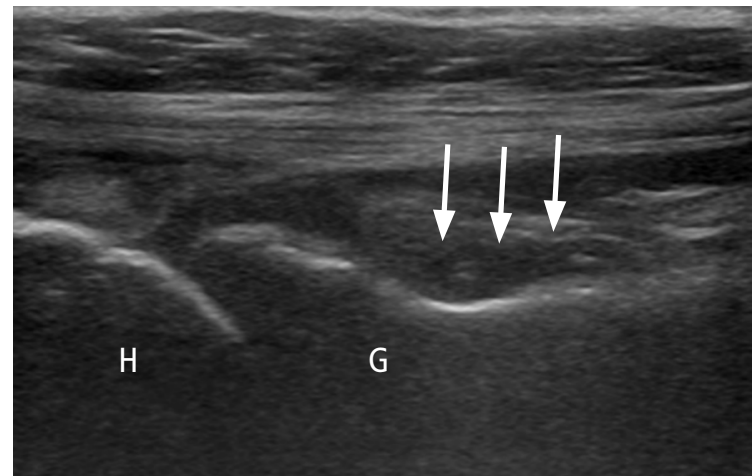

A

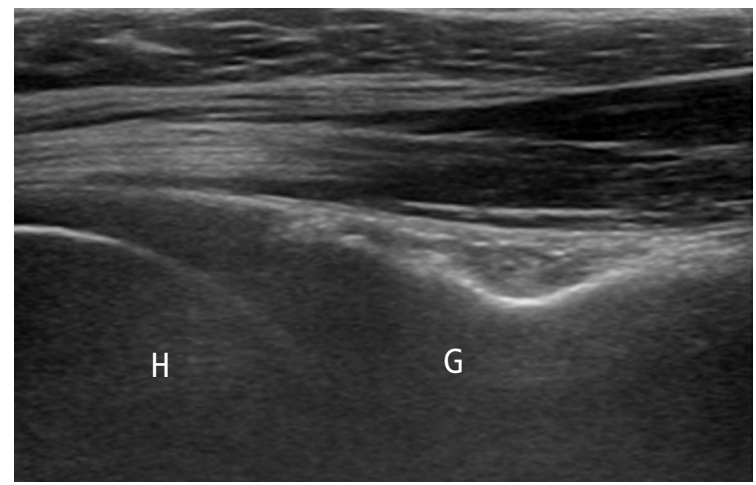

C

superficially located to the tendon. There are two ossifications in the subscapularis tendon. During internal rotation of the shoulder, the subscapularis tendon does not fully glide under the coracoid process due to the ossifications and subcoracoid impingement occurs. Note the hypoechoic soft tissue bulging contour by the subcoracoid bursa and the subscapularis tendon (https://doi.org/10.14366/usg.17055. v001).

Video clip 2. A 69-year-old woman with subcoracoid impingement with soft tissue involvement. On the long axis view of the subscapularis tendon, the thickened subcoracoid bursa is located superficial to the subscapularis tendon. During internal rotation of the shoulder, pooling of the fluid in the subcoracoid bursa is noted at the lateral aspect of the coracoid process. There is a smooth gliding of the subscapularis tendon underneath the coracoid process and the bursa, without significant impingement of the tendon (https://doi.org/10.14366/usg.17055.v002).

Video clip 3. A 31-year-old man without subacromial impingement. During the dynamic evaluation of subacromial impingement, there is no significant soft tissue or osseous impingement. The supraspinatus tendon and the greater tubercle show smooth passage underneath

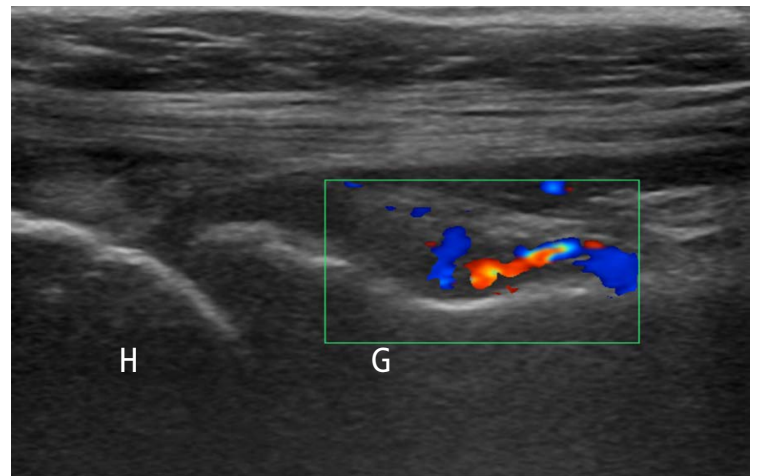

Fig. 11. A 70-year-old man with a dilated vein in the spinoglenoid notch (SGN).

A. A long-axis view of the posterior glenohumeral joint shows posterior glenohumeral joint recess and the spinoglenoid notch, which is located at just lateral of the glenoid. During external rotation of the shoulder, the distended suprascapular artery and veins (arrows) are seen as multiple anechoic structures in the SGN that can mimic a paralabral cyst. B. A color Doppler image shows vascularity within the dilated suprascapular vessels. C. Internal rotation of the shoulder collapses the suprascapular vein. We can distinguish the dilated vessels from a paralabral cyst, which does not collapse by internal rotation of the shoulder. $\mathrm{H}$, head of humerus; $\mathrm{G}$, glenoid.

the acromion (https://doi.org/10.14366/usg.17055.v003).

Video clip 4. A 45-year-old woman with grade 2 subacromial impingement. Long axis view of the supraspinatus tendon between acromion and greater tubercle shows subacromial-subdeltoid bursal thickening above supraspinatus tendon surface. During shoulder abduction, subacromial-subdeltoid bursal fluid pooling at the lateral aspect of acromion is seen. The humeral head normally moves inferiorly (https://doi.org/10.14366/usg.17055.v004).

Video clip 5. A 50-year-old woman with grade 3 subacromial impingement. Long axis view of supraspinatus tendon between acromion and greater tubercle shows severe tendinosis of supraspinatus tendon and adjacent thickened subacromialsubdeltoid bursa. During the dynamic examination, the osseous impingement occurs. The humeral head does not sufficiently move inferiorly and the supraspinatus tendon and subacromial-subdeltoid bursa cannot be passed underneath the acromion (https://doi. org/10.14366/usg.17055.v005).

Video clip 6. A 54-year-old man with adhesive capsulitis. Long axis view of the supraspinatus tendon during shoulder abduction 
shows limitation of supraspinatus movement beneath the acromion and continuous visualization of the supraspinatus tendon. There is no significant subacromial soft tissue impingement (https://doi. org/10.14366/usg.17055.v006).

\section{References}

1. Corazza A, Orlandi D, Fabbro E, Ferrero G, Messina C, Sartoris R, et al. Dynamic high-resolution ultrasound of the shoulder: how we do it. Eur J Radiol 2015;84:266-277.

2. Jacobson JA. Shoulder US: anatomy, technique, and scanning pitfalls. Radiology 2011;260:6-16.

3. Nazarian $L N$, Jacobson JA, Benson CB, Bancroft LW, Bedi $A$, McShane JM, et al. Imaging algorithms for evaluating suspected rotator cuff disease: Society of Radiologists in Ultrasound consensus conference statement. Radiology 2013;267:589-595.

4. Klauser AS, Tagliafico A, Allen GM, Boutry N, Campbell R, CourtPayen $\mathrm{M}$, et al. Clinical indications for musculoskeletal ultrasound: a Delphi-based consensus paper of the European Society of Musculoskeletal Radiology. Eur Radiol 2012;22:1140-1148.

5. de Jesus JO, Parker L, Frangos AJ, Nazarian LN. Accuracy of MRI, MR arthrography, and ultrasound in the diagnosis of rotator cuff tears: a meta-analysis. AJR Am J Roentgenol 2009;192:1701-1707.

6. Bianchi S, Martinoli C. Shoulder. In: Bianchi S, Martinoli C, eds. Ultrasound of the musculoskeletal system. Berlin: Springer, 2007;189-332.

7. Martinoli C. Musculoskeletal ultrasound: technical guidelines. Insights Imaging 2010;1:99-141.

8. Lee MH, Sheehan SE, Orwin JF, Lee KS. Comprehensive shoulder US examination: a standardized approach with multimodality correlation for common shoulder disease. Radiographics 2016;36:1606-1627.

9. Farin PU, Jaroma H, Harju A, Soimakallio S. Medial displacement of the biceps brachii tendon: evaluation with dynamic sonography during maximal external shoulder rotation. Radiology 1995; 195:845-848.

10. Farin PU. Sonography of the biceps tendon of the shoulder: normal and pathologic findings. J Clin Ultrasound 1996;24:309-316.

11. Read JW, Perko M. Shoulder ultrasound: diagnostic accuracy for impingement syndrome, rotator cuff tear, and biceps tendon pathology. J Shoulder Elbow Surg 1998;7:264-271.

12. Skendzel JG, Jacobson JA, Carpenter JE, Miller BS. Long head of biceps brachii tendon evaluation: accuracy of preoperative ultrasound. AJR Am J Roentgenol 2011;197:942-948.

13. Boileau P, Ahrens PM, Hatzidakis AM. Entrapment of the long head of the biceps tendon: the hourglass biceps: a cause of pain and locking of the shoulder. J Shoulder Elbow Surg 2004;13:249-257.

14. Pujol N, Hargunani R, Gadikoppula S, Holloway B, Ahrens PM.
Dynamic ultrasound assessment in the diagnosis of intra-articular entrapment of the biceps tendon (hourglass biceps): a preliminary investigation. Int J Shoulder Surg 2009;3:80-84.

15. Lappin M, Gallo A, Krzyzek M, Evans K, Chen YT. Sonographic findings in subcoracoid impingement syndrome: a case report and literature review. PM R 2017;9:204-209.

16. Garofalo R, Conti M, Massazza G, Cesari E, Vinci E, Castagna A. Subcoracoid impingement syndrome: a painful shoulder condition related to different pathologic factors. Musculoskelet Surg 2011;95 Suppl 1:S25-S29.

17. Martetschlager F, Rios D, Boykin RE, Giphart JE, de Waha A, Millett PJ. Coracoid impingement: current concepts. Knee Surg Sports Traumatol Arthrosc 2012;20:2148-2155.

18. Tracy MR, Trella TA, Nazarian LN, Tuohy CJ, Williams GR. Sonography of the coracohumeral interval: a potential technique for diagnosing coracoid impingement. J Ultrasound Med 2010;29:337-341.

19. Giaroli EL, Major NM, Lemley DE, Lee J. Coracohumeral interval imaging in subcoracoid impingement syndrome on MRI. AJR Am 」 Roentgenol 2006;186:242-246.

20. Drakes S, Thomas S, Kim S, Guerrero L, Lee SW. Ultrasonography of subcoracoid bursal impingement syndrome. PM R 2015;7:329-333.

21. Farin PU, Jaroma $H$, Harju A, Soimakallio S. Shoulder impingement syndrome: sonographic evaluation. Radiology 1990;176:845-849.

22. Coombs P, Ptasznik R. Sonography of the shoulder and upper arm. In: Introcaso J, van Holsbeeck M, eds. Musculoskeletal ultrasound. 3rd ed. New Delhi: Jaypee Brothers Medical Publishers, 2016;737811.

23. Bureau NJ, Beauchamp M, Cardinal E, Brassard P. Dynamic sonography evaluation of shoulder impingement syndrome. AJR Am J Roentgenol 2006;187:216-220.

24. Wang YC, Wang HK, Chen WS, Wang TG. Dynamic visualization of the coracoacromial ligament by ultrasound. Ultrasound Med Biol 2009;35:1242-1248.

25. Dietrich TJ, Jonczy M, Buck FM, Sutter R, Puskas GJ, Pfirrmann CW. Ultrasound of the coracoacromial ligament in asymptomatic volunteers and patients with shoulder impingement. Acta Radiol 2016;57:971-977.

26. Wu CH, Chang KV, Su PH, Kuo WH, Chen WS, Wang TG. Dynamic ultrasonography to evaluate coracoacromial ligament displacement during motion in shoulders with supraspinatus tendon tears. $J$ Orthop Res 2012;30:1430-1434.

27. Lee JC, Sykes C, Saifuddin A, Connell D. Adhesive capsulitis: sonographic changes in the rotator cuff interval with arthroscopic correlation. Skeletal Radiol 2005;34:522-527.

28. Homsi C, Bordalo-Rodrigues M, da Silva JJ, Stump XM. Ultrasound in adhesive capsulitis of the shoulder: is assessment of the coracohumeral ligament a valuable diagnostic tool? Skeletal Radio 2006;35:673-678.

29. Michelin P, Delarue Y, Duparc F, Dacher JN. Thickening of the inferior 
glenohumeral capsule: an ultrasound sign for shoulder capsular contracture. Eur Radiol 2013;23:2802-2806.

30. Ryu KN, Lee SW, Rhee YG, Lim JH. Adhesive capsulitis of the shoulder joint: usefulness of dynamic sonography. J Ultrasound Med 1993;12:445-449.

31. Ferri M, Finlay K, Popowich T, Jurriaans E, Friedman L. Sonographic examination of the acromioclavicular and sternoclavicular joints. J Clin Ultrasound 2005;33:345-355.

32. Petersson CJ, Redlund-Johnell I. Radiographic joint space in normal acromioclavicular joints. Acta Orthop Scand 1983;54:431-433.

33. Poncelet $E$, Demondion $X$, Lapegue F, Drizenko A, Cotten A, Francke JP. Anatomic and biometric study of the acromioclavicular joint by ultrasound. Surg Radiol Anat 2003;25:439-445.

34. Peetrons P, Bedard JP. Acromioclavicular joint injury: enhanced technique of examination with dynamic maneuver. J Clin Ultrasound 2007;35:262-267.

35. Kock HJ, Jurgens C, Hanke J, Schmit-Neuerburg KP. Standardized ultrasound examination for classification of instability of the acromioclavicular joint. Unfallchirurgie 1994;20:66-71.

36. Jacobson JA. Fundamentals of musculoskeletal ultrasound. 2nd ed. Philadelphia, PA: Elsevier Saunders, 2013.

37. Zubler V, Mamisch-Saupe N, Pfirrmann CW, Jost B, Zanetti M. Detection and quantification of glenohumeral joint effusion: reliability of ultrasound. Eur Radiol 2011;21:1858-1864.

38. Carroll KW, Helms CA, Otte MT, Moellken SM, Fritz R. Enlarged spinoglenoid notch veins causing suprascapular nerve compression. Skeletal Radiol 2003;32:72-77. 